\title{
Identifying Adaptation Options and Constraints: The Role of Agronomist Knowledge in Catchment Management Strategy
}

\author{
Tom Dolan • David J. Parsons • Peter Howsam • \\ Mick J. Whelan • Liz Varga
}

Received: 5 July 2013 / Accepted: 15 December 2013 /

Published online: 5 January 2014

C The Author(s) 2014. This article is published with open access at Springerlink.com

\begin{abstract}
Water suppliers in parts of Europe currently face occasional Drinking Water Directive compliance challenges for a number of pesticide active substances including metaldehyde, clopyralid and propyzamide. Water Framework Directive (WFD) Article 7 promotes a prevention-led (catchment management) approach to such issues. At the same time, European pesticide legislation is driving reduced active substance availability. In this context, embedding agronomic drivers of pesticide use into catchment management and regulatory decision making processes can help to ensure that water quality problems are addressed at source without imposition of disproportionate cost on either agriculture or potable water suppliers. In this study agronomist knowledge, perception and expectations of current and possible future pesticide use was assessed and the significance of this knowledge to other stakeholders involved with pesticide catchment management was evaluated. This was then used to provide insight into the possible impacts of active substance restrictions and associated adaptation options. For many arable crops, further restrictions on the range of pesticides available may cause increased use of alternatives (with potential for "pollution swapping"). However, in many cases alternatives are not available, too costly or lack a proven track record and other adaptation options may be selected which catchment managers need to be able to anticipate.
\end{abstract}

Keywords Catchment management $\cdot$ Water framework directive $\cdot$ Agronomist $\cdot$ Adaptation options $\cdot$ Drinking water $\cdot$ Pesticides

Electronic supplementary material The online version of this article (doi:10.1007/s11269-013-0498-6) contains supplementary material, which is available to authorized users.

T. Dolan $\cdot$ D. J. Parsons $(\bowtie) \cdot$ P. Howsam

Institute for Environment, Health, Risks and Futures, School of Applied Sciences, Cranfield University, Cranfield, Bedford, Bedfordshire MK43 0AL, UK

e-mail: d.parsons@cranfield.ac.uk

M. J. Whelan

Department of Geography, University of Leicester, Leicester LE1 7RH, UK

L. Varga

Complex Systems Research Centre, School of Management, Cranfield University, Cranfield, Bedford, Bedfordshire MK43 0AL, UK 


\section{Introduction}

The European Water Framework Directive (WFD) Article 7 (EC 2000) promotes a preventionled approach to Drinking Water Directive (DWD) (EC 1998) compliance (Dolan et al. 2012, 2013a, b). This is philosophically consistent with the World Health Organisation (WHO) drinking water safety planning (DWSP) approach (World Health Organisation 2008), which aims to increase understanding of and mitigate risks from catchment to consumer (Breach 2011). For water quality parameters that are influenced by diffuse source pollution, this usually implies a catchment management approach to address the causes rather than just the symptoms of a water quality problem. For agricultural diffuse pollution of 'raw' (untreated) water, effective catchment management must be based on an understanding of agricultural decision making processes. This is particularly pertinent in the case of pesticides, where several widelyused active substances regularly cause water quality problems in a number of drinking water catchments (Kennedy 2010; Kennedy et al. 2009; Defra 2012). These problems are especially acute for compounds that are not removed significantly by current water treatment technologies, such as metaldehyde (Autin et al. 2012) and clopyralid (Tizaoui et al. 2011).

The catchment management literature for pesticides and potable water predominantly focuses on understanding the many factors (e.g. soil type, topography, local climate, drainage, seasonal weather conditions) that influence the complex pathways along which pesticides are transported from land to water (Brown and van Beinum 2009; Reichenberger et al. 2007; Tediosi et al. 2012, 2013). However, there is less focus in the literature on embedding understanding of behaviour at source, i.e. those contextual factors that drive current pesticide use patterns, which will also shape future pesticide requirements, into water supplier or regulator decision making processes (Blackstock et al. 2010).

Agronomists often provide expert advice to farmers to support the management of weed, disease and pest problems. In the UK agronomists are the main decision makers for pesticide use on $84 \%$ of UK arable farms (Twining and Simpson 2009). As a group, they are, consequently, very influential in determining pesticide use patterns and how agriculture will respond to future challenges, such as changes in active substance availability or the need to reduce diffuse pollution. Agronomist expertise could, therefore, be invaluable to all European water suppliers and regulators if methods for regular consultation were developed to systematically embed knowledge of local agronomy issues into catchment management planning. Shared understanding of the challenges faced by water suppliers and the WFD competent authority would also be beneficial for agriculture (Dolan et al. 2013a). Increased engagement between these stakeholders is essential if solutions to diffuse pesticide pollution problems that avoid the risk of "pollution swapping" (Stevens and Quinton 2009a, b) or the imposition of disproportionate cost on either water suppliers or agriculture are to be identified.

This paper presents the findings from a three-stage study of agronomist knowledge, perception and expectations. The principal aim of the study was to identify drivers of current operational pesticide use, potential agronomic impacts of restrictions or bans on active substances, potential responses (adaptation options) to such restrictions and constraints on adaptation options. The principal outputs from this study are insights into agricultural decision making and an adaptation options framework which, when combined with knowledge of current pesticide strategies and constraints to adaptation, can be used as the basis for catchment management dialogue between key stakeholders.

The study was conducted in the Anglian region of Eastern England (see Online Resource 1 for a map of the study area), which has a very high area of productive arable land and high pesticide use, occasionally resulting in DWD compliance challenges for the water industry. Although the work was focussed on the agronomy of arable crops, the general methodology 
and many of the principal outcomes are relevant to any situation in Europe where diffuse pesticide pollution is causing problems for DWD compliance and preventative action is required under WFD Article 7.

\section{Methods}

\subsection{General}

The study was conducted in three stages. At each stage, themes that emerged from the previous stage were developed and validated. Stage 1 was a scoping exercise, based on semi-structured interviews, during which 16 agronomists identified the weed, pest and disease problems of greatest significance to the area in which they work and the most commonly used methods to manage these. Stage 2 used seven case study active substances to investigate the confidence with which respondents could identify the availability (or not) of alternative management options and predict how agronomists and farmers might respond if an active substance were restricted or lost. Stage 3 used an online survey to validate 43 trend statements that arose from Stages 1 and 2 against a wider population of 94 respondents. At each stage the survey was piloted with academic colleagues and a representative from an agricultural industry body.

\subsection{Stage 1}

A semi-structured interview template (Coolican 2009; Bryman 2012) to examine the main crops, problems (weeds, pests and diseases) and solutions (pesticide and non-pesticide) was used for the Stage 1 interviews (Online Resource 2). When setting questions, the decision was taken to allow respondents to identify crops, weeds, pests and diseases, and not to ask directly about any pesticide active substances. The purpose was to derive maximum benefit from expert knowledge and avoid guiding the interview onto any specific active substances or issues (thereby minimising bias).

Sixteen interviews of 60-90 min were conducted. Interviews were performed face-to-face or by telephone by the same researcher. In all cases the semi-structured questionnaire was shared with the respondent at least 1 week in advance of the interview. The role of the interviewer was to allow the interview to develop based upon the semi-structured template. The interviewer used judgement to decide when to ask additional questions to prompt further detail or clarify information provided, and when to direct the interview back to the semistructured template. Given the range of specialist knowledge amongst interviewees and a time constraint on the interview, not all topics were covered with all respondents, and some topics were covered in greater depth by individual respondents.

The interview transcripts were analysed using thematic template analysis (King 2004) against an 'a priori' template based on the semi-structured interview template. Grounded theory (Lansisalmi et al. 2004) was not used because the 'a priori' template implies preconceived expectations regarding responses. The creation of an 'a posteriori' template was used to identify themes emerging from the interview (King 2004; Braun and Clarke 2006). A tally of the number of times each heading in the 'a posteriori' template arose across the 16 interviews was used to assess the prevalence of a theme. Prevalence was used as a proxy for relative importance, but not to establish the validity of a theme.

To support identification of case study active substances for Stage 2, further analysis of relative use levels, future regulatory status and the extent to which the active substance is present in, or is expected to be present in raw (untreated) water was undertaken for all active 
substances identified during Stage 1 (Garthwaite et al. 2008; The Food and Environment Research Agency 2009; PSD 2009; The Voluntary Initiative 2013).

\subsection{Stage 2}

Stage 2 of the study used seven case study active substances to investigate possible responses to plausible changes in active substance availability. The principal aims were to learn more about how agriculture might respond to the loss of specific active substances, how confidently agronomy experts could predict future adaptations and the available adaptation options (given the range of currently approved active substances) if an active substance was lost or restricted. The herbicides propyzamide, carbetamide, mesosulfuron-methyl, clopyralid, pendimethalin, chlortoluron and the molluscicide metaldehyde were selected for inclusion in Stage 2. To be selected, an active substance had to be used extensively in the Anglian region (Online Resource 1) and to be subject to one or more of the following criteria that could plausibly restrict future availability:

- The pesticide is a potential challenge for water company compliance with the DWD without the adoption of enhanced treatment technologies.

- The pesticide will potentially not be reapproved under EU pesticide approval Regulation $1107 / 2009$ (EC 2009) and there is reason to suspect that replacements might cause water quality problems.

- The efficacy of the pesticide is threatened by the emergence of resistance which means that alternatives might be needed in the future.

A standard set of questions to identify the current reasons for use, potential pesticide and non pesticide alternatives, respondent confidence in the alternatives identified and the broader impacts on crop yield and quality, if the pesticide in question were not available, was used for each active substance (Online Resource 2). The questions required respondents to consider plausible future changes to pesticide availability and to give personal judgement rather than a definitive answer. To encourage respondents to evaluate the level of confidence they placed on each answer, a confidence scale was designed into the question structure. A four-point scale (not at all, low, medium, high) using internally consistent, non-overlapping categories that covered the full range of certainties was selected (Cassell and Symon 2004; Strauss and Corbin 1990).

Eleven interviews were conducted using the protocol defined at Stage 1. Template analysis was used to analyse all interview transcripts (King 2004). Because the question set was more tightly defined than at Stage 1, the 'a posteriori' template did not differ greatly from the initial 'a priori' template. Analysis led to the identification of a number of key findings for further validation in the Stage 3 survey. Additionally, Stage 2 analysis led to the proposal of an 'adaptation options preference framework' to predict the options which agriculture would explore when faced with pressure on, restriction or loss of an active substance. This framework was originally proposed in (Dolan et al. 2013a) and has subsequently been refined and tested during Stage 3 of this study (see Section 4.2).

\subsection{Stage 3}

Stage 3 used an online survey to validate findings from Stages 1 and 2 using a larger sample of agronomy experts. The Stage 3 survey included 43 Likert items, each comprising a 'stem' (the question), and a five point Likert response scale - strongly disagree, disagree, neither agree nor disagree, agree, strongly agree (Online Resource 3). Likert items can be evaluated as 
standalone statements (Dunlap et al. 2000; Hovardas and Poirazidis 2007) and response patterns across a number of Likert items can be used to test pre-defined Likert scale hypotheses. Six pre-defined Likert hypotheses were included in the Stage 3 design. The purpose of Stage 3 was to identify areas of consensus where there is widespread agreement between agronomy experts, areas where there is sufficient uncertainty that no consensus can be reached and the presence of and possible reasons for 'outliers' (respondents answering against consensus).

In order to avoid ambiguous or unclear Likert items, the 'stem' of each item contained only one attitudinal object, and no quantitative statements (John 2012). A five point Likert response scale allowed respondents to express agreement or disagreement, without introducing ambiguity through too many response categories. Acquiescence bias, 'the tendency to agree with statements to some extent irrespective of their content' (John 2012) has been identified as a potential problem in the design of surveys based upon Likert items. To avoid a unidirectional survey and reduce the risk of acquiescence bias, at least one negatively worded Likert item was included in each section. Furthermore, three pairs of similar but opposite Likert items to test for acquiescence bias and two Likert item pairs to test for internal consistency were included in the survey. Spearman's rank correlation test for ordinal data was used (Field 2009).

Comment boxes to identify reasons for consensus and outliers were included after every section of the survey. 'Outliers' are of interest to the research because solutions to problems may diffuse from niche to mainstream as they become proven or more widely known (Taleb 2008; Rogers 2003).

To maximise the response rate, Stage 3 was designed to take no more than $15 \mathrm{~min}$, and a brief justification of the purpose of the study was provided. The survey was distributed over a 6 month period with support of professional agronomy organisations.

All the analyses in this study treated the Likert response scale data as ordinal values and applied non-parametric statistics (Kuzon et al. 1996; Jamieson 2004). However, some authors have argued that it is possible to apply parametric methods provided that certain conditions are met (Carifio and Perla 2008).

The Likert response scale data from Stage 3 were analysed in three ways.

(1) Spearman's rank correlation tests $(\alpha=0.05)$ and a visual inspection of data were used to test for acquiescence bias and internal consistency (Field 2009).

(2) A frequency distribution was created for each Likert item and chi-squared 'goodness of fit' tests $(\alpha=0.05)$, were performed to evaluate the null hypothesis $\left(\mathrm{H}_{\mathrm{n}}\right)$ against an alternative hypothesis $\left(\mathrm{H}_{\mathrm{a}}\right)$, where:

$\mathbf{H}_{\mathbf{n}}$ : There is no consensus in responses to the Likert item.

$\mathbf{H}_{\mathbf{a}}$ : There is a consensus in responses to the Likert item.

To conduct the chi-squared test, the five point Likert response scale was converted into a two point scale consisting of 'agreement' or 'disagreement'. All 'Agree' and 'Strongly Agree' responses were classed as agreement; all 'Disagree' and 'Strongly Disagree' responses were classed as disagreement. The response 'Neither' was excluded from the population $(n)$. Where $H_{n}$ was rejected, a direction ('Agree' or 'Disagree') was assigned to $H_{a}$ based upon visual inspection of the number of agreement and disagreement responses.

(3) The results from (2) were applied to test six pre-defined Likert scale hypotheses based upon combinations of three to eight Likert items. No appropriate technique was identified for the summation of ordinal data because, whilst numerical values can be assigned to the categories to rank order, these values cannot give an indication of magnitude. Therefore, 
a technique based upon examination of individual Likert items was used to reach conclusions. It is acknowledged that any Type I or Type II errors at Likert item level will also impact on this examination of Likert scale hypotheses. Conclusions are, therefore, taken as indicative not definitive. The same approach was applied to test a series of pre-defined hypotheses for each case study active substance.

\section{Results}

\subsection{Stage 1 and 2 Findings}

Analysis of Stage 1 and 2 interviews identified the following agronomy basics, features of the combinable crop rotation (i.e. crops harvested using a combine harvester) and impacts of pesticide and water regulation as knowledge all water companies and regulators should possess.

\subsubsection{Basic Agronomic Features}

Soil type, the availability of break crops, and the comparative economics of cropping options drive the structure of any agricultural enterprise. Different farm types (combinable, horticultural, grassland, potatoes, sugarbeet) each have associated pesticide use profiles. To understand the agronomic drivers of pesticide use, one must, therefore, understand the structure of the rotation deployed by the farm enterprise, and the nature of weed, pest and disease problems within that rotation.

Pesticides are costly inputs, so pesticide use will usually be recommended only where the cost of action is anticipated to be less than the cost of inaction. Many control strategies involve more than one active substance applied at one or more stages throughout the growing season or across the entire rotation in which the crop is grown. Some strategies may provide incidental management of other less troublesome problems. For example, a strategy to control blackgrass (Alopecurus agrestis L.) (Table 1) may control other grass weed species. Additionally, the management of resistance to pesticide active substances is an important consideration when designing a control strategy.

Restricting or banning an active substance does not address the root cause of the water quality problem - the need to combat a particular, and probably widespread, weed, disease or pest issueand is likely to trigger an increased use of one or more other active substances throughout the rotation to manage that issue (i.e. "pollution swapping" may occur (Stevens and Quinton 2009a, b)).

\subsubsection{The Combinable Crop Rotation}

Heavy clay soils occur widely across the case study region. On these soils the dominant cropping pattern is currently an autumn sown combinable crop rotation based on 2 years of winter wheat (Triticum aestivum) followed by 1 year of oilseed rape (OSR: Brassica napus L.), or a similar variation.

Blackgrass and the risk of herbicide-resistant blackgrass need to be managed by a programme of herbicide applications every year of the rotation (Table 1). In order to maximize the level of control achieved and reduce the risk of resistance, it is often important to use several active substances with different modes of action in a control programme. Different active substances are used in the wheat and OSR phases of the rotation; the herbicide active substances used in OSR (i.e. propyzamide and carbetamide) are particularly important 
Table 1 An example of a rotation-wide control strategy for herbicide-resistant blackgrass

\begin{tabular}{|c|c|}
\hline Winter wheat & Winter OSR \\
\hline Stale seedbed & Stale seedbed \\
\hline $\begin{array}{l}\text { Delay drilling to allow a stale seedbed followed by application of a } \\
\text { non-selective herbicide, typically glyphosate, to kill any weeds } \\
\text { which have germinated before drilling. }\end{array}$ & $\begin{array}{l}\text { NB: This is not widely used because OSR } \\
\text { is drilled earlier than wheat. }\end{array}$ \\
\hline Pre-emergence treatment & Pre-emergence treatment \\
\hline $\begin{array}{l}\text { Apply residual herbicides at the pre-emergence stage. Stack (apply) } \\
\text { a range of actives based upon a flufenacet base (10/10). Other } \\
\text { residual herbicides for inclusion in the stack include: }\end{array}$ & $\begin{array}{l}\text { - Metazachlor }(7 / 10) \\
\text { - Metazachlor + quinmerac }(3 / 10)\end{array}$ \\
\hline $\begin{array}{l}\text { - Diflufenican }(10 / 10) \\
\text { - Pendimethalin }(10 / 10) \\
\text { - Triallate }(5 / 10) \\
\text { - Prosulfocarb }(6 / 10) \\
\text { - CTU }(2 / 10) \\
\text { - Flurtamone }(1 / 10)\end{array}$ & $\begin{array}{l}\text { - Metazachlor }+ \text { quinmerac }+ \\
\text { dimethanimid }-\mathrm{p}(2 / 10)\end{array}$ \\
\hline Post-emergence treatment & Post-emergence treatment \\
\hline $\begin{array}{l}\text { Atlantis (mesosulfuron-methyl + iodosulfuron-methyl) is the dom- } \\
\text { inant product }(10 / 10) \text {. }\end{array}$ & $\begin{array}{l}\text { Propyzamide AND/OR Carbetamide (10/ } \\
\text { 10) } \\
\text { Tepraloxydim and cycloxydim can be used } \\
\text { as support }(1 / 10)\end{array}$ \\
\hline
\end{tabular}

because, at present, there is no known resistance to these compounds. Many of the herbicides used for blackgrass control (Table 1) are residual (designed to persist in the soil) and applied to bare soil. The risk of water quality issues is often higher with these herbicides than with many others because they do not typically degrade sufficiently before the arrival of rainfall capable of mobilising them and transporting them to surface waters (Tediosi et al. 2012).

Slugs are a major pest problem every year in the combinable crop rotation. Slug pellets containing metaldehyde are considered to be the most cost-effective method of control.

Table 1 gives an example of a rotation-wide programme of control for herbicide-resistant blackgrass. The programme is based primarily on the use of pesticides, but is increasingly receiving support from complementary non-pesticide actions such as "stale seedbeds" and delayed drilling.

\subsubsection{The Impact of Regulation on Pesticide Use Patterns}

Current patterns of pesticide active substance use, and any associated water quality problems, are shaped by a context of decreasing active substance availability since the introduction of EU pesticide approval Directive 91/414/EEC (EC 1991). The new approval legislation, EU Regulation 1107/2009 (EC 2009), will further reduce the number of active substances available (PSD 2009), and is a significant source of uncertainty because future adaptations cannot be planned without clarity regarding which active substances will be lost and which will remain available.

Additionally, agronomists perceive the WFD to be a further source of uncertainty and potentially, a driver of decreased active substance availability. Therefore, agronomists expressed the view that any regulator or water company action for WFD Article 7 compliance must understand the causes (the reasons for use, constraints on alternative options, and impacts of losses) and not just focus on the symptoms. 


\subsection{Stage 3 Results}

\subsubsection{Introduction}

Ninety-four agronomists completed the Stage 3 survey. Full details of the responses to all the Likert items are provided online (Online Resource 4). The following are presented here:

- Six hypotheses based upon multiple Likert items (Section 3.2.2).

- Synopses of findings specific to the case study active substances (Section 3.2.3).

- Single Likert items that support additional themes (Section 3.2.4).

Additionally, brief details of the tests performed to assess acquiescence bias and internal consistency are given in Sections 3.2.5.

\subsubsection{Hypotheses (Likert Scale) Based Upon Multiple Likert Items}

The hypotheses presented in Table 2 were tested against multiple Likert items. Each hypothesis is relevant to the full range of approved active substances and beyond the geographical context of this study.

\subsubsection{Active Substances Specific Findings}

Brief synopses for each of the seven case study active substances included in Stage 3 are given below.

Propyzamide and carbetamide: Propyzamide, and to an extent carbetamide, are crucial to blackgrass management in a combinable crop rotation on heavy soil. Without these active substances it would be difficult to grow OSR or any other autumn break crop, so

Table 2 Hypotheses based on multiple Likert items (three or more)

\begin{tabular}{|c|c|c|}
\hline Hypothesis & $\begin{array}{l}\text { Number of Likert } \\
\text { items to test hypothesis }\end{array}$ & $\begin{array}{l}\text { Likert items } \\
\text { supporting } \\
\text { hypotheses }\end{array}$ \\
\hline There are no direct substitutes for currently used herbicides. & 4 & $100 \%$ \\
\hline $\begin{array}{l}\text { Cultural control is a complement to not substitute for pesticide } \\
\text { active substances }\end{array}$ & 5 & $100 \%$ \\
\hline $\begin{array}{l}\text { Herbicide losses in wheat will lead to increased dependence } \\
\text { on currently available pre-emergence herbicides }\end{array}$ & 8 & $100 \%$ \\
\hline $\begin{array}{l}\text { Effective resistance management requires as many modes of } \\
\text { action as possible }\end{array}$ & 5 & $100 \%$ \\
\hline $\begin{array}{l}\text { The order of preference for adaptation to the loss of a pesticide } \\
\text { active substance is: substitute pesticides, alternative } \\
\text { pesticide in rotation, cultural control, crop architecture, } \\
\text { rotational control }\end{array}$ & 8 & $100 \%$ \\
\hline $\begin{array}{l}\text { The development of new active substances takes time (at least } \\
5 \text { years), and is not triggered in response to the potential } \\
\text { loss of a currently approved active substance. The loss of } \\
\text { active substances does not create an incentive for new } \\
\text { pesticide active substances to come to market }\end{array}$ & 3 & $100 \%$ \\
\hline
\end{tabular}


rotational change based upon increased spring cropping might occur. It is uncertain whether carbetamide could substitute directly for propyzamide.

Metaldehyde: Cultural control options cannot eliminate the need for slug pellets. Substitutes for metaldehyde are available. If metaldehyde were restricted for any reason, increased use of these substitutes could prevent rotational change. However, agronomist comments express concern regarding the relative cost, efficacy, availability, proven track record and environmental impact of these possible substitutes.

Mesosulfuron-methyl ('Atlantis'): Reduced efficacy of post-emergence blackgrass control in wheat will reduce wheat yields and increase the use of pre-emergence herbicides. Cultural control options are inadequate to cover for reduced efficacy; if control was too difficult, a change to the rotation might be considered.

Clopyralid: Clopyralid is the only herbicide available for the control of sow thistles. Cultural control is largely ineffective. If clopyralid were unavailable where sow thistles are a particular problem, OSR yields would decrease and reduced OSR planting might occur.

Pendimethalin and chlortoluron: Blackgrass control depends upon many active substances and different modes of action to increase total efficacy and reduce resistance risk. The loss of one active substance would have impacts on how others were used.

\subsubsection{Likert Items on General Themes}

Five conclusions based on a single Likert item can also be drawn from this study, these are:

- When one active substance is lost (for whatever reason) other active substance(s) will be used to manage the weed, pest or disease issue.

- In the absence of effective pesticide control, weed and pest pressures will increase over time.

- The agronomic impact of losing an active substance depends on which active substances remain available.

- No new herbicides for blackgrass are likely to be available in the next 5 years.

- A change to the rotation is the intervention of last resort.

\subsubsection{Tests for Acquiescence Bias and Internal Consistency}

In all cases, the tests for acquiescence bias and internal consistency using Spearman's rank correlation coefficient showed internally consistent responses and the absence of acquiescence bias (Online Resource 4 Table 8).

\section{Discussion}

\subsection{Agronomic Adaptation Options and Preferences}

On the basis of Likert scale Hypothesis E, Fig. 1 is proposed as a framework to rank, in order of preference, the adaptation options agronomy can consider when any active substance is restricted or withdrawn. Typically the lower the preference for an adaptation option the higher will be the capital or operating cost of implementing it. This framework is relevant for: 


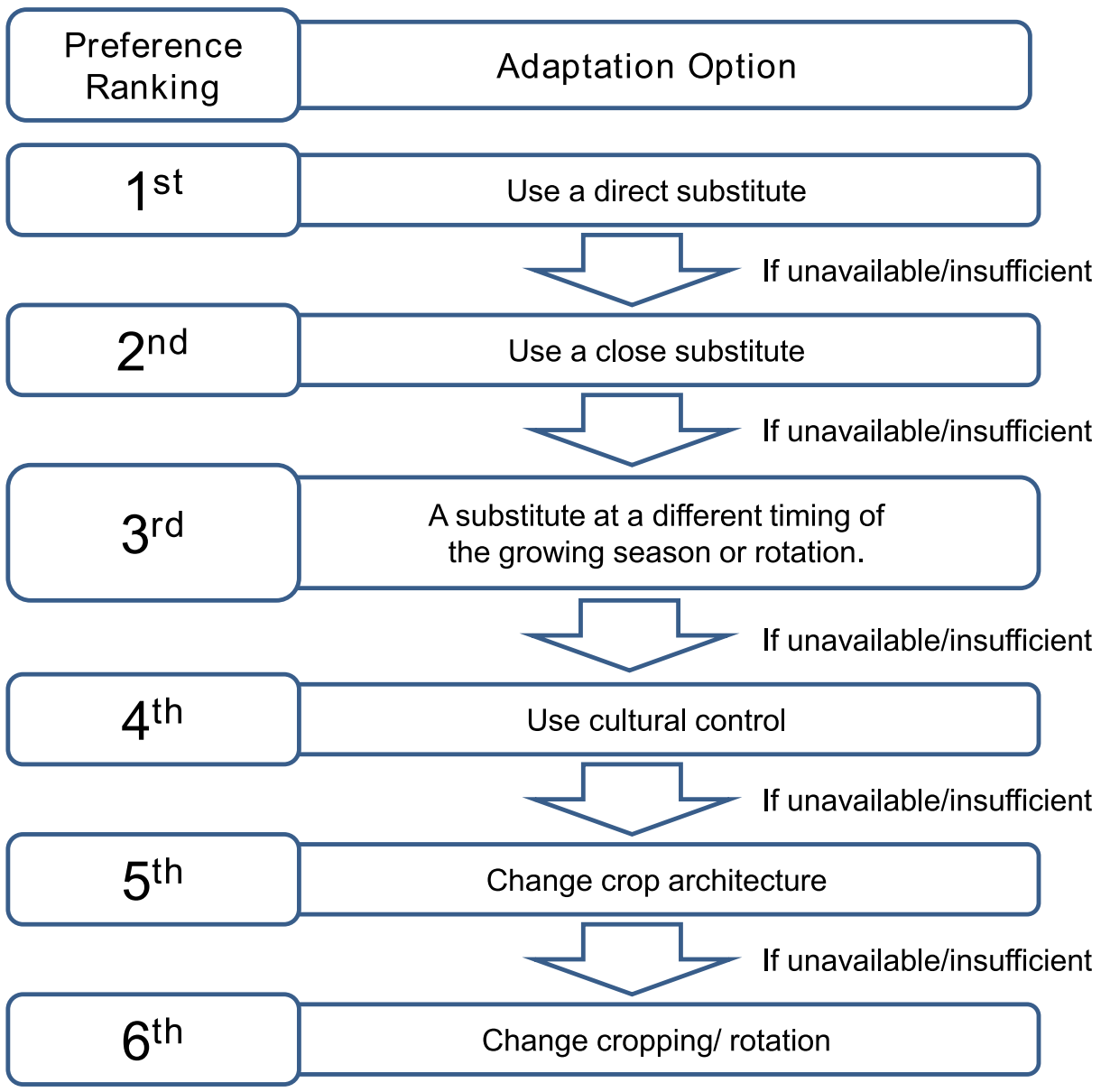

Fig. 1 Adaptation option preference framework

- Agronomists who need to explain the practical ramifications of the loss of any active substance.

- Regulators who need to understand the ramifications of any decision to restrict active substance availability.

- Water suppliers who need to anticipate which active substances to expect in 'raw' water in the future.

Where agriculture perceives that an active substance may be restricted in the future and that voluntary action can prevent the threat of statutory restriction, actions in the framework may be initiated on a voluntary basis. For example the Voluntary Initiative in England and Wales was initiated in 2001 as a partnership between industry and government with the aim of reducing diffuse pesticide pollution through voluntary good practice (Garrod et al. 2007; The Voluntary Initiative 2013); the Metaldehyde Stewardship Group promotes a similar approach for metaldehyde (Metaldehyde Stewardship Group 2013). However, the level of voluntary action available to agriculture is constrained by other practical factors (Section 4.3). 
1st Preference: Use a direct substitute. A direct substitute is a pesticide active substance with an equally established agronomic track record that can be applied at the same stage in the rotation with equally efficacy at an equivalent cost. Likert scale Hypothesis A indicates that direct substitutes are very rare. Metaldehyde for slug control illustrates the rarity of direct substitutes: methiocarb and ferric phosphate were identified as possible alternatives and at least one was rated as similarly efficacious. However, neither substance can be considered as a direct substitute because agronomists identify strong reservations regarding the relative cost, relative efficacy, environmental impact (methiocarb), availability of supply and lack of proven track record (ferric phosphate).

2nd Preference: Use a close substitute. A close substitute is an active substance that could potentially replace a currently used active substance at similar timing but differs to some degree in terms of one or more factors from efficacy, cost, proven track record and environmental impact.

Likert scale Hypothesis D establishes the need for multiple modes of action to manage resistance, and Table 1 illustrates the need for a range of active substances, to be used in some circumstances, to maximise the level of control achieved. Therefore, a distinction is needed between close substitutes and those active substances already used as part of a programme of control alongside the active substance in question. For example, flufenacet and diflufenican (Table 1) are complements rather than substitutes, because blackgrass control is most effective when these residual herbicides are used in combination (Shah et al. 2012; Hull and Moss 2012). Thus, in reality, close substitutes are also rare.

3rd Preference: A substitute at a different timing in the rotation. Similar to a close substitute but applied at a different timing. A prominent example of this is given by Likert scale Hypothesis C, where in the absence of direct or close substitutes, agronomists have begun to adapt to the decreased efficacy of the post-emergence herbicide mesosulfuronmethyl ('Atlantis') by combining more pre-emergence herbicides.

The 1st, 2nd and 3rd adaptation options all relate to replacing one active substance with another. However, the feasibility of these options is constrained by the availability of active substance chemistry. Likert scale Hypothesis F, agronomist comments and information from the literature (Shah et al. 2012) identify a shortage of new active substances coming to market, decreased availability of active substances as a result of European pesticide legislation and the perception that WFD Article 7 may potentially further-restrict active substance availability. Therefore, before restricting any active substance a regulator must consider whether sufficient (and appropriate) alternatives are available to provide equivalent control, at an equivalent cost with lower environmental and DWD compliance risks. Similar considerations must be made by any water company implementing a catchment management strategy based upon promotion of active substance substitution.

Several agronomists in the survey expected the loss of active substances to be particularly acute for horticulture, because it is dependent on specific off-label approvals (SOLAs) of active substances originally developed for other crop types, and it is costly (relative to the returns achievable), to register an active substance for minor use.

4th Preference: Use cultural control. Cultural control is the use of cultivation practices without a fundamental change to the rotation, to improve control and preventatively manage disease, weed or pest problems. Cultural control options are increasingly becoming part of an integrated control strategy (Hull and Moss 2012; Neale 2012). Examples include compaction of seed beds to reduce slug risk, the use of rotational ploughing to bury weed seeds and stale seed beds with glyphosate to reduce weed levels prior to crop drilling (Table 1). However, Likert Hypothesis B concludes that these actions should be a 
complement to, and not a substitute for pesticide use. This may be explained by poor efficacy and reliability in comparison to pesticides, as (Moss 2010) observes 'Nonchemical control methods have mean efficacy levels equivalent to a very poor [pesticide] product, but often at a premium price'.

5th Preference: Change crop architecture. This intervention avoids the need for a change to the rotation by changing the approach to the management of one or more crops in the rotation. Current UK research is investigating whether precision spraying techniques can be applied to manage blackgrass using a non-selective herbicide such as glyphosate between wide rows of OSR, thereby restricting propyzamide and carbetamide use solely to the cultivated area (Ballinghall 2013). At present the agronomist community is uncertain whether this type of intervention will reduce water quality problems caused by certain active substances. Reasons for this uncertainty are threefold: research to develop selective spraying techniques is ongoing; work to establish the optimal row width for OSR is yet to be completed; whether only applying propyzamide and carbetamide to the cultivated area will reduce movement to water is has not been investigated. If selective spraying techniques are perfected and made commercially available, it is possible that they could be transferable to other crops.

6th Preference: Change cropping/rotation. Although this intervention was identified as a last resort, it may occur if the other options fail, if the cost of a cropping change is less than adopting one of the other options (1-5), or if the expected benefit from changing the rotation outweighs the short term cost. There are three possible types of cropping change: a different crop grown in the same growing season, a spring crop introduced into the rotation in place of an autumn sown crop and the introduction of an occasional fallow into the rotation. Moss and Hull (2012) confirm agronomist comments that the potential for spring cropping is limited by the suitability of land, relative economics, the difficulty of establishing subsequent crops and the availability of active substances to manage weeds emerging in spring.

The adaptation options framework assumes all factors other than active substance availability will remain constant. However, exogenous factors have the potential to disrupt relative preferences for the adaptation options. Examples of such factors include global commodity prices, changes to elements of European policy (e.g. CAP reform, GMO policy, drinking water standards for pesticide active substances and incentive payments for energy crops) and technical developments making certain crops easier to produce.

\subsection{Using the Current Strategy to Anticipate Adaptation}

From responses to the Likert items it can be concluded that agronomists believe that alternative active substances will be used in increased quantities if others are lost or restricted, that few new active substances are coming to market (Likert scale Hypothesis F) and that cultural control cannot completely replace a lost active substance (Likert scale Hypotheses B). It follows that the loss of any active substance will increase pressure on other active substances in a control strategy. Consequently, pollution swapping may be an outcome of a poorly designed mitigation strategy.

Knowledge of the strategies used to control the main problems in all the major rotations (similar to Table 1 for blackgrass) and the adaptation options framework (Fig. 1) provide a foundation from which regulators and water companies can anticipate the possible impacts of action to address any water quality issue for pesticides. It is, therefore, in the shared interest of 
water companies, regulators and agronomists to compile this information for all rotations before discussing how to alleviate any water quality issues arising from active substance use in those rotations.

\subsection{Constraints to Adaptation}

This study confirmed that current agricultural practices aim to maximize gross margins, minimize the risk of crop failure and prevent the development of resistance to any active substance. The ability to do this is constrained by soil type, topography, weather conditions, active substance availability, the availability of alternative crops and environmental impact. A number of factors constrain the level of voluntary adaptation possible:

- The availability (or not) and cost of direct substitutes, close substitutes, or substances for use elsewhere in the rotation.

- The availability, efficacy, time and cost of cultural control options.

- The need to manage the risk of resistance.

- The need to avoid short term risk in the current crop.

- Reluctance to use unproven solutions in place of proven solutions.

- The risks and cost of spring cropping.

'Cost' in any of the above refers not just to purchase or implementation cost relative to the current solution, but also includes the opportunity cost of yield foregone from making the adaptation. Water companies and regulators must be aware of these constraints and work with agronomists to identify feasible options in response to arising water quality problems caused by pesticides, and actions that overcome any of these constraints.

\subsection{Messages for Catchment Management}

A number of key messages for catchment management emerge from this study; these findings are applicable to all European Member states concerned with WFD Article 7 compliance:

- Restrictions on active substances will have knock-on effects for the use of other active substances and in many cases on agricultural productivity. How adaptation occurs and the scale of the impact will depend on the context of active substance availability at the time of any restriction and whether adaptation preferences 1, 2 and 3 (Fig. 1) are available.

- In the majority of cases, the active substances being used are those which are most effective and the agricultural benefits of application outweigh purchase and application costs.

- Catchment management based upon product substitution is unlikely to engage pesticide users if it is voluntary, and it would impose costs on agriculture, if it were statutory.

- Cultural control options are an increasingly important element of a control programme, but are unlikely to replace active substance use (Likert scale Hypothesis B).

- The use of the adaptation option preference framework (Fig. 1) coupled with a knowledge of the agricultural drivers for pesticide use to tackle a particular problem in a particular rotation (e.g. Table 1), can provide a foundation for regulators and water companies to anticipate the possible impacts of action to address any water quality issue for pesticides.

- Both farmers and water companies need to take a long term, whole rotation perspective on the cost of inaction, compared to the cost of action (Moss and Hull 2012). Where costs must be incurred, evidence of a long term benefit must be available. 


\section{Conclusions}

Agronomists cannot predict with confidence how agriculture would respond to active substance losses or restrictions. However, in general, the loss of one active substance will lead to the increased use of others creating a risk of pollution swapping. Therefore, water companies face considerable uncertainty when planning for pesticide management in the potable water supply. To support the prevention-led approach to DWD compliance required by WFD Article 7, water suppliers and regulators need to work closely with agronomists to chart control strategies for the major weed, disease and pest problems in their catchments (similar to Table 1). Application of the adaptation options preference framework (Fig. 1) to these strategies can strengthen water company and regulator knowledge of reasons for pesticide use and provide a useful basis for catchment management dialogue between key catchment stakeholders to identify appropriate management actions.

This study highlights the challenges of embedding expertise from one industry into the decision making processes of another. This challenge is relevant to both agriculture and water companies, because water company decision making on catchment management will potentially have an impact on both industries (Dolan et al. 2013a). Policy makers and regulators face a similar challenge when devising policy options to address the water quality impacts of diffuse pesticide pollution (Defra 2012).

Acknowledgments The authors would like to acknowledge the support of Anglian Water Services Ltd and the EPSRC for funding the EngD research on which this article is based.

Open Access This article is distributed under the terms of the Creative Commons Attribution License which permits any use, distribution, and reproduction in any medium, provided the original author(s) and the source are credited.

\section{References}

Autin O, Hart J, Jarvis P, MacAdam J, Parsons SA, Jefferson B (2012) Comparison of UV/ $\mathrm{H}_{2} \mathrm{O}_{2}$ and UV/TiO 2 for the degradation of metaldehyde: kinetics and the impact of background organics. Water Res 46:56555662

Ballinghall M (2013) New approaches to weed control in oilseed rape. HGCA. http://www.hgca.com/cms publications.output/2/2/Publications/Publication/New $\% 20$ approaches $\% 20$ to $\% 20$ weed $\% 20$ control $\% 20$ in $\%$ 20oilseed\%20rape.mspx? $\mathrm{fn}=$ show\&pubcon=7517. Accessed 15 May 2013

Blackstock KL et al (2010) Understanding and influencing behaviour change by farmers to improve water quality. Sci Total Environ 408:5631-5638

Braun V, Clarke V (2006) Using thematic analysis in psychology. Qual Res Psychol 3:77-101

Breach RA (2011) Why water safety plans and the Bonn charter. In: Breach RA (ed) Drinking water quality management from catchment to consumer: a practical guide for utilities based on water safety plans, $1 \mathrm{st}$ edn. IWA, London, pp 1-12

Brown CD, van Beinum W (2009) Pesticide transport via sub-surface drains in Europe. Environ Pollut 157: $3314-3324$

Bryman A (2012) Social research methods, 4th edn. OUP, Oxford

Carifio J, Perla R (2008) Resolving the 50-year debate around using and misusing Likert scales. Med Educ 42: $1150-1152$

Cassell C, Symon G (2004) Essential guide to qualitative methods in organisational research. Sage Publications Ltd, London

Coolican H (2009) Research methods and statistics in psychology, 5th edn. Hodder Education, London

Defra (2012) Appraisal of cost effective policy instruments to tackle the impact from pesticides - WT0963. Defra. http://randd.defra.gov.uk/Default.aspx?Menu=Menu\&Module=More\&Location=None\&Completed= 0\&ProjectID=18180. Accessed 29 March 2013 
Dolan T, Howsam P, Parsons DJ (2012) Diffuse pesticide pollution of drinking water sources: impact of legislation and UK responses. Water Policy 14:680-693

Dolan et al. (2013a) Impact of WFD Article 7 on DWD compliance for pesticides: challenges of a prevention-led approach. Water Policy (submitted 26/10/13)

Dolan et al (2013b) Is the EU drinking water standard for pesticides in drinking water consistent with the precautionary principle? Environ Sci Technol 47:4999-5006

Dunlap RE, Van Liere KD, Mertig AG, Jones RE (2000) New trends in measuring environmental attitudes: measuring endorsement of the new ecological paradigm: a revised NEP scale. J Soc Issues 56:425-442

EC (European Communities) (1991) Directive 91/414/EEC concerning the placing of plant protection products on the market. OJ L 230, 15 July 1991

EC (European Communities) (2000) Directive 2000/60/EC establishing a framework for Community action in the field of water policy. OJ L 327, 23 October 2000

EC (European Communities) (2009) Regulation 1107/2009 concerning the placing of plant protection products on the market. OJ, L 309/1, 21 October 2009

EC (European Communities) Directive $98 / 83 / \mathrm{EC}$ on the quality of water intended for human consumption. OJ L 330/32, 3 November 1998

Field A (2009) Discovering statistics using SPSS (introducing statistical methods series), 3rd edn. SAGE Publications Ltd, London

Garrod GD et al (2007) A mixed methodology framework for the assessment of the voluntary initiative. Pest Manag Sci 63:157-170

Garthwaite DG, Thomas MR, Parrish G, Smith L, Barker I (2008) Pesticide usage survey report 224: arable crops in Britain. FERA, York

Hovardas T, Poirazidis K (2007) Environmental policy beliefs of stakeholders in protected area management. Environ Manag 39:515-525

Hull R, Moss SR (2012) Is the increasing reliance on residual herbicide for black-grass (alopecurus myosuroides) control sustainable? In: Orson J (ed) Crop protection in southern Britain, aspects of applied biology 117. Association of Applied Biologists, Warwick, p 25

Jamieson S (2004) Likert scales: how to (ab)use them. Med Educ 38:1217-1218

John R (2012) Likert items and scales. surveynet.ac.uk/sqb/datacollection/likertfactsheet.pdf. Accessed 9 April 2013

Kennedy J (2010) Pesticides and the impact of the Water Framework Directive. In: 47th Annual BCPC Weeds Review, Peterborough, pp 40-50

Kennedy J, Varma A, Foo V (2009) A study to identify cost-effective measures for plant protection products causing non-compliance with Water Framework Directive objectives, GEHO0109BPGF-E-E. Environment Agency. http://publications.environment-agency.gov.uk/dispay.php?name=GEHO0109BPGF-E-E. Accessed 15 May 2013

King N (2004) Using templates in thematic analysis of text. In: Cassell C, Symon G (eds) Essential guide to qualitative methods in organisational research. Sage Publications Ltd, London, pp 256-270

Kuzon WM, Urbanchek MG, McCabe S (1996) The seven deadly sins of statistical analysis. J Oral Maxillofac Surg 37:265-272

Lansisalmi H, Peiro J, Kivimaki M (2004) Grounded theory in organisational research. In: Cassell C, Symon G (eds) Essential guide to qualitative methods in organisational research. Sage Publications Ltd, London, pp 242-255

Metaldehyde Stewardship Group (2013) Get Pelletwise!. MSG. http://www.getpelletwise.co.uk. Accessed 8 March 2013

Moss SR (2010) Non-chemical methods of weed control: benefits and limitations. In: Zydenbos SM (ed) 17th Australasian weed conference. CAWs, Christchurch, pp 14-19

Moss SR, Hull R (2012) Quantifying the benefits of spring cropping for control of Alopecurus Myosuroides (black-grass). In: Orson J (ed) Crop protection in southern Britain, aspects of applied biology 117. Association of Applied Biologists, Warwick, p 1

Neale D (2012) Optimising the cultural control of black-grass (Alopecurus Myosuroides). In: Orson J (ed) Crop protection in Southern Britain, aspects of applied biology 117. Association of Applied Biologists, Warwick, p 7

PSD (2009) Proposal for a regulation of the European Parliament and of the Council concerning the placing of plant protection products on the market: summary impact assessment. PSD, York

Reichenberger S, Bach M, Skitschak A, Frede H (2007) Mitigation strategies to reduce pesticide inputs into ground- and surface water and their effectiveness: a review. Sci Total Environ 384:1-35

Rogers EM (2003) Diffusion of innovations, 5th edn. Simon and Schuster International, New York

Shah S, Lloyd C, Corbett S, Southgate J (2012) Use of different cultivation systems and herbicide programmes as a part of an integrated black-grass (Alopecurus Myosuroides) control solution in winter wheat. In: Orson J 
(ed) Crop protection in Southern Britain, aspects of applied biology 117. Association of Applied Biologists, Warwick, p 15

Stevens CJ, Quinton JN (2009a) Diffuse pollution swapping in arable agricultural systems. Crit Rev Environ Sci Technol 39:478-520

Stevens CJ, Quinton JN (2009b) Policy implications of pollution swapping. Phys Chem Earth 34:589-594

Strauss A, Corbin J (1990) Basics of qualitative research: grounded theory procedure and techniques. Sage Publications Ltd., London

Taleb NN (2008) The black swan. Penguin, London

Tediosi A, Whelan MJ, Rushton KR, Thompson TRE, Gandolfi C, Pullan SP (2012) Measurement and conceptual modelling of herbicide transport to field drains in a heavy clay soil with implications for catchment-scale water quality management. Sci Total Environ 438:103-112

Tediosi A, Whelan MJ, Rushton KR, Gandolfi C (2013) Predicting rapid herbicide leaching to surface waters from an artificially drained headwater catchment using a one dimensional two-domain model coupled with a simple groundwater model. J Contam Hydrol 145:67-81

The Food and Environment Research Agency (2009) Pesticide usage statistics. http://pusstats.csl.gov.uk/index. cfm. Accessed 8 December 2012

The Voluntary Initiative (2013) The voluntary initiative: promoting responsible pesticide use. http://www. voluntaryinitiative.org.uk/. Accessed 15 May 2013

Tizaoui C, Mezughi K, Bickley R (2011) Heterogeneous photocatalytic removal of the herbicide clopyralid and its comparison with UV/H2O2 and ozone oxidation techniques. Desalination 273:197-204

Twining S, Simpson D (2009) Pesticide practices survey UK. http://www.pesticides.gov.uk/Resources/CRD/ Migrated-Resources/Documents/U/UKPesticidePracticesReport.pdf. Accessed 20 May 2013

World Health Organisation (2008) Guidelines for drinking-water quality: third edition incorporating the first and second addenda. WHO, Geneva 